Подотрасль растениеводства в области представлена производством зерна, овощей, сои и картофеля. В целях определения подкомплекса, обладающего наибольшим потенциалом для создания кластера в сельскохозяйственной отрасли Амурской области, были рассчитаны коэффициенты локализации по производимым культурам за 2012-2016 гг. (таблица 4).

Таблий 4

Коэффициенты локализации производства основных сельскохозяйственных культур в

\begin{tabular}{|} 
Амурской области, 2012-2016 г2. \\
\begin{tabular}{|c|c|c|c|c|c|}
\hline $\begin{array}{c}\text { Сельскохозяйственные } \\
\text { культуры }\end{array}$ & 2012 г. & 2013 г. & 2014 г. & 2015 г. & 2016 г. \\
\hline Зерновые & 0,45 & 0,31 & 0,43 & 0,37 & 0,41 \\
\hline в том числе: & \multicolumn{5}{|l|}{} \\
\hline пшеница & 0,45 & 0,28 & 0,37 & 0,36 & 0,40 \\
\hline гречиха & 1,87 & 0,46 & 1,35 & 0,91 & 0,51 \\
\hline ячмень & 0,44 & 0,30 & 0,31 & 0,25 & 0,32 \\
\hline овес & 1,07 & 0,65 & 1,28 & 0,76 & 1,07 \\
\hline Соя & 54,58 & 43,50 & 49,01 & 40,92 & 30,22 \\
\hline Овощи & 0,56 & 0,40 & 0,48 & 0,48 & 0,43 \\
\hline Картофель & 1,18 & 0,65 & 1,03 & 0,94 & 0,92 \\
\hline
\end{tabular}
\end{tabular}

Значение коэффициента локализации производства сои за рассматриваемый период значительно превышает остальные показатели, свидетельствуя о высокой концентрации соеводства в регионе. В Амурской области располагается более 40 \% от общероссийских посевных площадей, что делает её абсолютным лидером среди других соесеящих регионов страны. В настоящее время производство сои является самым эффективным направлением сельского хозяйства в Амурской области. Доходность этого подкомплекса позволяет предприятиям не только вести расширенное воспроизводство, но и покрывать убыточные направления деятельности. Поэтому считаем целесообразным формирование на территории Амурской области соевого кластера который в последствии позволит повысить конкурентоспособность агропромышленного комплекса и экономики региона в целом.

$$
* * *
$$

1. Портер М. Конкуренция / М. Портер. - М.: Изд. дом «Вильямс», 2010. - С. 235-238.

2. Карлина Т.В. Идентификация ядер региональных экономических кластеров на основе анализа структурных сдвигов в условиях циклично развивающейся экономики // Вестник Пермского университета. - 2011. - № 4(11). - С. 18-29

3. Садыкова Э.Ц. Кластерный подход к идентификации специализации региона / Э.Ц. Садыкова, Э.В. Базарова // Вестник Восточно-Сибирского государственного университета технологий и управления. - 2015. - № 5. - С. 115-119.

4. Пашина Л.Л. Оценка кластерного потенциала соевого подкомплекса Амурской области / Малашонок А.А., Пашина Л.Л. // Вестник Воронежского государственного университета. - 2017. № 1 (52). - C. 199-206

\title{
Чернопятов А.М.
}

Развитие государственного сектора в российской федерации на современном этапе Сургутский государственный педагогический университет doi 10.18411/gq-30-11-2017-31

(Россия, Сургут)

idsp 000001:gq-30-11-2017-31

\section{Аннотация}

В статье автором рассматривается степень участия государства в строительстве экономике страны, ее удельный вес в общем плане. Раскрываются особенности участия 
государственного сектора с применением статистических данных, что позволяет более объективно оценивать роль государственного сектора на современном этапе.

Ключевые слова: государство, экономика, собственность, промышленность, страна, сектор.

Государственный сектор Российской Федерации на современном этапе остается доминирующим в топливно-энергетическом и оборонном комплексах, медицинской и микробиологической промышленности, в сфере транспорта и связи. Наименьшее распространение частная форма собственности получила в отраслях естественных монополий - железнодорожном транспорте и электроэнергетике. Эти отрасли почти во всех странах служат традиционной нишей для государственного предпринимательства или государственно-частного партнерства, можно утверждать, что Россия шла и идет в общем русле развития мировой экономики.

Здесь необходимо уточнить, что данный тезис носит общий характер, и его необходимо будет уточнять. Во-первых, в последнее время ослабляются позиции государства в традиционных сегментах. Во-вторых, истинные различия в строении отечественного государственного сектора просматриваются при сравнении более детализированных отраслевых структур[12].

Наиболее болезненным сегментом российского государственного сектора с полным основанием можно считать его промышленную часть, то акцентируем внимание именно на ней, при этом сведения о государственном секторе не очень точны и не полны, так как постоянно меняется обстановка, но позволяют показать общую картину (табл. 1 и 2).

Таблица 1

Относительные масштабы государственного сектора России- 2005г. (в \%)

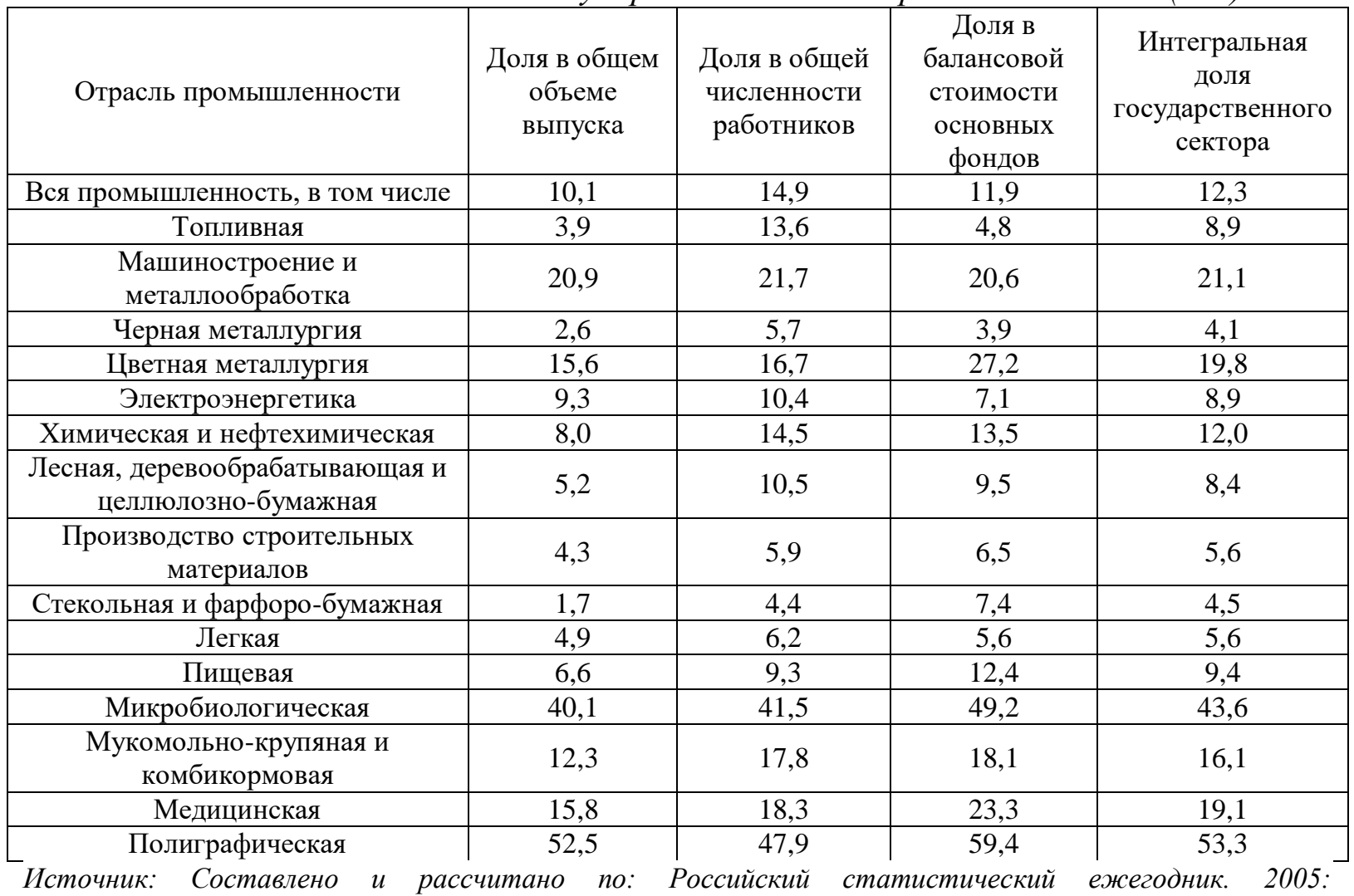

Cтат.сб./Росстат. М., 2005.

В следующей таблице 2 представляем статистические данные по доле государственного сектора в 2015 году. 
Относительные масштабы государственного сектора России с учетом

Таблица 2 муниципального - 2015г. (в \%)

\begin{tabular}{|c|c|c|c|c|}
\hline Отрасли промышленности & $\begin{array}{c}\text { Доля в общем } \\
\text { объеме } \\
\text { выпуска }\end{array}$ & $\begin{array}{c}\text { Доля в общей } \\
\text { численности } \\
\text { работников }\end{array}$ & $\begin{array}{c}\text { Доля в } \\
\text { балансовой } \\
\text { стоимости } \\
\text { основных } \\
\text { фондов }\end{array}$ & $\begin{array}{c}\text { Интегральная } \\
\text { доля } \\
\text { государственного } \\
\text { сектора }\end{array}$ \\
\hline Вся промышленность & 3,71 & 27,13 & 18,0 & 16,28 \\
\hline
\end{tabular}

Источник: Составлено и рассчитано по: Россия в ицифрах. 2016: Kрат.стат.сб./Росстат- М., 2016 $543 c$.

Как видно из табличных данных, государственный сектор во всех отраслях представлен в небольших объемах, но есть налицо рост по всем показателям кроме доли в общем объеме выпуска продукции, по сравнению с 2005 годом. Хотя по разным данным, уже к 2010г. доля государственного сектора достигла более 75\%. Интересный момент, откуда взялась такая цифра? Не будем много цитировать, а приведем лишь один пример из официального источника Правительства РФ. "Так, по некоторым экспертным оценкам, в последнее десятилетие роль госсектора в российской экономике усиливается, а вклад госкомпаний и государства как субъекта бюджетных расходов в ВВП России в 2015 г. достигает $70 \%$ против $35 \%$ в 2005 году[1,15]. В статье "Государева доля"[2], признают, что государственные компании и государство контролируют 70\% российской экономики. В данном случае, наша противоположная точка зрения гласит об другом. Государственное участие в целом в экономике страны минимальное (табл. 3, 4 и 5).

Таблица 3

Основные фонды по формам собственности(на конец года; по полной учетной стоимости)

\begin{tabular}{|c|c|c|c|c|c|c|}
\hline \multirow{3}{*}{ Годы } & \multicolumn{3}{|c|}{ Млн. руб. (1990 г. - млрд. руб.) } & \multicolumn{3}{|c|}{ В процентах к итогу } \\
\hline & \multirow[t]{2}{*}{$\begin{array}{c}\text { все основные } \\
\text { фонды }\end{array}$} & \multicolumn{2}{|c|}{$\begin{array}{c}\text { в том числе } \\
\text { по формам собственности }\end{array}$} & \multirow[t]{2}{*}{$\begin{array}{c}\text { все } \\
\text { основные } \\
\text { фонды }\end{array}$} & \multicolumn{2}{|c|}{$\begin{array}{c}\text { в том числе } \\
\text { по формам } \\
\text { собственности }\end{array}$} \\
\hline & & $\begin{array}{c}\text { государственн } \\
\text { ая }\end{array}$ & $\begin{array}{c}\text { негосударст- } \\
\text { венная }\end{array}$ & & \begin{tabular}{|c|} 
государстве \\
нная
\end{tabular} & $\begin{array}{c}\text { негосударс } \\
\text { твенная }\end{array}$ \\
\hline 1990 & 1927 & 1754 & 173 & 100 & 91 & 9 \\
\hline 2000 & 17464172 & 4366043 & 13098729 & 100 & 25 & 75 \\
\hline 2010 & 93185612 & 17705266 & 75480346 & 100 & 19 & 81 \\
\hline 2011 & 108001247 & 19440224 & 88561023 & 100 & 18 & 82 \\
\hline 2012 & 121268908 & 21828403 & 99440505 & 100 & 18 & 82 \\
\hline 2013 & 133521531 & 24033876 & 109487655 & 100 & 18 & 82 \\
\hline 2014 & 147429656 & 26537338 & 120892318 & 100 & 18 & 82 \\
\hline 2015 & 160725261 & 28930547 & 131794714 & 100 & 18 & 82 \\
\hline
\end{tabular}

Источник: Российский статистический ежегодник. 2016: Стат.сб./Росстат. -М., 2016 - 725 c.

Как видим из данных представленных в таблице, соотношение основных фондов к негосударственным находится на уровне 18:82. Картина явно не в пользу государственного сектора.

В таблице 4 приводим данные Росстата по числу организаций по формам собственности.

Таблийа 4

Число организащий из них по формам собственности в 2015 году (на конец года)

\begin{tabular}{|c|c|c|c|c|c|}
\hline & \multicolumn{2}{|c|}{ Число организаций } & \multicolumn{2}{|c|}{ Из них по формам собственности } \\
\hline & тысяч & $\begin{array}{c}\text { в процентах к } \\
\text { итогу }\end{array}$ & $\begin{array}{c}\text { государственная } \\
\text { и муниципальная }\end{array}$ & частная & смешанная \\
\hline Всего, тыс. & 4732,1 & 100 & 322,7 & 4377,8 & 31,6 \\
\hline $\begin{array}{c}\text { Всего, в } \\
\text { прцентах к } \\
\text { итогу }\end{array}$ & 4732,1 & 100 & 6,82 & 92,51 & 0,67 \\
\hline
\end{tabular}

Источник: Составлено и рассчитано по: Россия в ичифрах. 2016: Kрат.стат.сб./Росстат- M., 2016 $543 c$. 
В общем срезе представляем статистические данные в табл. 5 и 6.

Таблий 5

Распределение предприятий и организаџиий по формам собственности

(на конеи года)

\begin{tabular}{|c|c|c|c|c|c|c|c|c|}
\hline & \multicolumn{8}{|c|}{ Тыс. предприятий и организаций } \\
\hline Годы & 2000 & 2005 & 2010 & 2011 & 2012 & 2013 & 2014 & 2015 \\
\hline $\begin{array}{c}\text { Число } \\
\text { предприятий и } \\
\text { организаций } \\
\text { всего } \\
\text { в т.ч. по формам } \\
\text { собственности: }\end{array}$ & 3346,5 & 4767,3 & 4823,3 & 4866,6 & 4886,4 & 4843,4 & 4886,0 & 5043,6 \\
\hline государственная & 150,8 & 160,4 & 119,4 & 115,5 & 112,6 & 116,1 & 113,7 & 110,7 \\
\hline муниципальные & 216,6 & 252,1 & 246,4 & 239,5 & 230,9 & 225,3 & 218,9 & 212,0 \\
\hline частная & 2509,6 & 3837,6 & 4103,6 & 4164,6 & 4195,0 & 4159,5 & 4212,2 & 4377,8 \\
\hline $\begin{array}{c}\text { собственность } \\
\text { общественных и } \\
\text { религиозных } \\
\text { организаций } \\
\text { (объединений) }\end{array}$ & 223,0 & 252,5 & 157,0 & 149,6 & 147,3 & 144,9 & 144,4 & 145,4 \\
\hline $\begin{array}{c}\text { прочие формы } \\
\text { собственности, } \\
\text { включая } \\
\text { смешанную } \\
\text { российскую, } \\
\text { собственность } \\
\text { государственных } \\
\text { корпораций, } \\
\text { иностранную, } \\
\text { совместную } \\
\text { российскую и } \\
\text { иностранную }\end{array}$ & 246,5 & 264,7 & 196,8 & 197,4 & 200,6 & 197,6 & 196,7 & 197,7 \\
\hline
\end{tabular}

Источник: Россия в циифрах. 2016: Kрат.стат.сб./Росстат- М.2016 - 543 c.

В таблице 6 мы представляем статистические данные для большей наглядности в процентах к итогу.

Таблица 6

Распределение предприятий и организаций по формам собственности (на конец года)

\begin{tabular}{|c|c|c|c|c|c|c|c|c|}
\hline & \multicolumn{7}{|c|}{ В процентах к итогу } \\
\hline Годы & 2000 & 2005 & 2010 & 2011 & 2012 & 2013 & 2014 & 2015 \\
\hline $\begin{array}{c}\text { Число } \\
\text { предприятий и } \\
\text { организаций всего } \\
\text { в т.ч. по формам } \\
\text { собственности: }\end{array}$ & 100 & 100 & 100 & 100 & 100 & 100 & 100 & 100 \\
\hline государственная & 4,5 & 3,4 & 2,5 & 2,4 & 2,3 & 2,4 & 2,3 & 2,2 \\
\hline муниципальные & 6,5 & 5,3 & 5,1 & 4,9 & 4,7 & 4,7 & 4,5 & 4,2 \\
\hline частная & 75,0 & 80,5 & 85,1 & 85,6 & 85,9 & 85,9 & 86,2 & 86,8 \\
\hline $\begin{array}{c}\text { собственность } \\
\text { общестенных и } \\
\text { религиозных } \\
\text { организаций } \\
\text { (объединений) }\end{array}$ & 6,7 & 5,3 & 3,3 & 3,1 & 3,0 & 3,0 & 3,0 & 2,9 \\
\hline $\begin{array}{c}\text { прочие формы } \\
\text { собственности, } \\
\text { включая } \\
\text { смешанную } \\
\text { российскую, } \\
\text { собственность }\end{array}$ & 7,4 & 5,6 & 4,1 & 4,1 & 4,1 & 4,1 & 4,0 & 3,9 \\
\hline
\end{tabular}



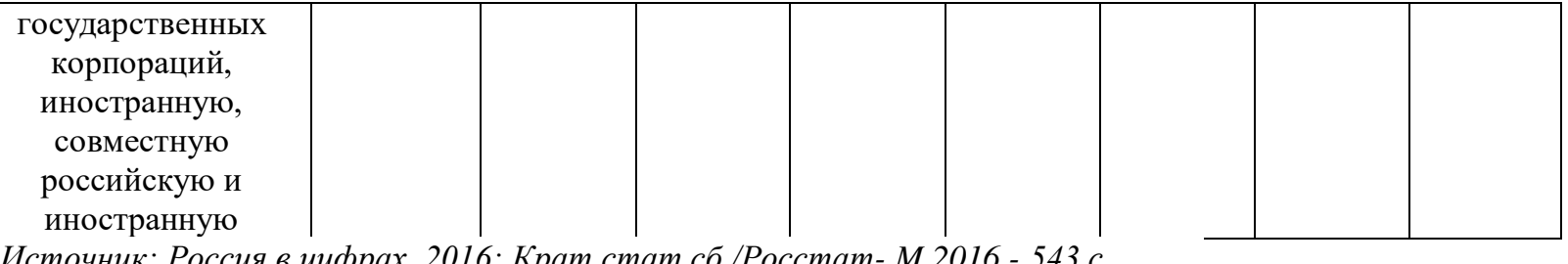

Источник: Россия в ичифрах. 2016: Крат.стат.сб./Росстат- M.2016 - 543 c.

Частный сектор в отличие от государственного старается не показывать полностью свои доходы, есть предприятия, которые подают только декларации, но не выполняют работ. Большая доля теневого сектора в частном секторе существенно влияет на объем ВВП страны, который в случае выхода из тени частного сектора может увеличиться более чем на $15 \%[4,13]$. Одной из слабостей правительства состоит в том, что государство напрямую лишило себя основного рычага управления и модернизации национальной промышленности. Здесь необходимы особые институциональные подходы, один из них - это жесткие гарантии на частную собственность, что даст возможность частному капиталу инвестировать в экономику своих предприятий.

Практически во всех странах государственный сектор представляет собой неоднородное производственно образование. Анализ опыта зарубежных стран показывает, что унифицированных подходов применительно к государственному сектору экономики нет. В одних странах он очень большой (Греция, Италия, Франция, Швеция), в других - почти отсутствует (Япония, Люксембург) или полностью отсутствует - (Гонконг), где-то сконцентрирован на небольших участках (Голландия). В некоторых странах он высокоэффективен (Швеция, Франция), в других- менее эффективен (США, Бельгия). Доля в США прямого государственного производства находится в пределах $12 \%$ национального выпуска - это один из минимальных среди аналогичных показателей развитых стран мира[6,10,11,14,15].

В настоящее время выделяются три модели государственного сектора: западноевропейская (Франция, Португалия и ряд других стран, причем в связи с кризисом Португалия в 2010г. находится на стадии дефолта), североамериканская (США и Канада) и азиатская (Япония и Южная Корея)[3,7,8]. Для западноевропейской модели в основном характерен довольно большой по объему высокоэффективный щедро финансируемый государственный сектор, имеющий весьма разнообразную, отраслевую структуру; для североамериканской - специализирующийся главным образом на чисто государственных функциях, обороне и социальной инфраструктуре исходя из системы экономного финансирования.

Обеим моделям присуща четкая грань между частным бизнесом и государством. Для азиатской же модели эта грань размыта, переплетение интересов государства и бизнеса идет через представителей во властных и корпоративных структурах. Существует формально небольшой государственный сектор, которому государство оказывает ощутимую финансовую помощь.

Между тем, в условиях инновационности и модернизации изменение макроэкономических показателей, отражающих особенности отраслевой организации экономики, не отражает в полной мере происходящих изменений.

$* * *$

1. Государственное участие в российской экономике: госкомпании, закупки, приватизация [Электронный peсурс] // Бюллетень о развитии конкуренции: Аналитический центр при Правительстве Российской Федерации. - $2016 \quad$ (март). $\quad$ №13. URL:http://ac.gov.ru/files/publication/a/8449.pdf (Дата обращения: 02.07.2016).

2. Балацкий Е.В. Элементы экономики государственного сектора [Электронный ресурс]. - URL: http://kapital-rus.ru/articles/article/elementy_ekonomiki_gosudarstvennogo_sektora/ (Дата обращения: 04.07.2016). 
3. Шумаев В.А. Совершенствование управления государственным сектором экономики с учетом опыта зарубежных стран / В.А. Шумаев // Механизация строительства. - 2013. - №10 (832). - С.4952.

4. О развитии государственного сектора экономики Российской Федерации [Электронный ресурс] / Федеральная служба государственной статистики [2011-2013 гг.]. - URL: http://sophist.hse.ru/rstat/ (Дата обращения: 22.07.2016).

5. Мау В. Российская экономика в 2015 году. Тенденции и перспективы. (Вып. 37) / В. Мау и др.; под ред. Синельникова-Мурылева С.Г. (гл. ред.), Радыгина А.Д.; Ин-т экономической политики им.Е.Т. Гайдара. - М.: Изд-во Ин-та Гайдара, 2016. - 472 с.

6. Чернопятов А.М. Теория организации. Учебное пособие для студентов высших учебных заведений/Советский, 2010.

7. Чернопятов А.M. Маркетинг персонала. Raleigh , North Carolina, 2016.

8. Чернопятов А.М. Функционирование финансового механизма предприятия. Советский, 2012.

9. Чернопятов А.М. Механизмы совершенствования институциональной среды российского предпринимательства в сфере налогообложения. Международный научно-исследовательский журнал. 2015. №7-3(38). С.109-111.

10. Чернопятов А.М. Влияние налогового института на предпринимательскую деятельность. Транспортное дело России. 2010. №7. С.145-148.

11. Чернопятов А.М. Функциональная составляющая в области государственного регулирования предпринимательства. Транспортное дело России. 2014. №6-2. С.42-43.

12. Чернопятов А.М. Формирование современной экономики России. Инновационная экономика: информация, аналитика, прогнозы. 2016. №1. С.66.

13. Чернопятов А.М. Роль институтов государства в организации национальной хозяйственной системы. Транспортное дело России. 2016. №1. С.87-90.

14. Кондратьев В. Второе дыхание государственного капитализма / В. Кондратьев // Мировая экономика и международные отношения. - 2013. - № 6. - С. 3-18.

15. Муравьев С.Р. Государственный сектор российской экономики: оценка масштабов и эффективности производства // Экономика и бизнес: теория и практика. - 2016. - №7. - С. 54-60. 